\title{
Specific Features and Problem Aspects of Adapting the Taxi Market Regulatory Mechanism to Business Models Built on Digital Platforms
}

\author{
Erchak A.I. \\ Belarus State Economic University \\ Minsk, Republic of Belarus \\ erchak_a@bseu.by \\ Mikulich I.M. \\ Belarus State Economic University \\ Minsk, Republic of Belarus \\ mikulich@bseu.by
}

\author{
Gavrilenko V.A. \\ Yaroslav-the-Wise Novgorod State University \\ Veliky Novgorod, Russia \\ Saint-Petersburg University of State Fire Service of \\ Emercom of Russia \\ Saint-Petersburg, Russia \\ gv22@mail.ru \\ Trofimova M.S. \\ Yaroslav-the-Wise Novgorod State University \\ Veliky Novgorod, Russia \\ rina23@inbox.ru
}

\begin{abstract}
The article reflects the results of a study of the Belarusian taxi market and trends in its development. The authors highlight the specific features, patterns of its development, as well as the problems of functioning and regulation in the context of the rapid spread of digital platforms and business models based on digital data. The survey of taxi drivers made it possible to determine the common features and differences in the organization of work of drivers of traditional taxi operators and drivers who provide taxi services in the framework of interaction with digital platforms. When assessing the effectiveness and efficiency of market regulation, the problem field of application and specific features of the functioning of the taxi market in the Republic of Belarus were identified, as well as directions for solving the identified problems were developed. The set of measures of state regulation of the taxi market considered in the article will allow for obtaining a significant effect in the field of reducing the level of costs, providing additional revenues to the budget, reducing the degree of cross-subsidization of urban passenger transport, and also ensuring a balance of interests of the state, entrepreneurs and the population in the field of transportation. The approbation of the developments and the information obtained as a result will make it possible to extend this mechanism to the regulation of the irregular road transport market, or to modify certain elements and methods of interaction in order to achieve harmonization and balance of interests.
\end{abstract}

Keywords-taxi market, regulatory mechanism, business models, digital platforms

\section{INTRODUCTION}

The development of digital platforms has led to the transformation of many product markets. Such changes often turn out to be caused not so much by the introduction of technological innovations as by the innovators' proposal of fundamentally different business models, in comparison with which the old business organization turns out to be archaic and uncompetitive. The emergence of transport network companies such as Uber and Yandex on the Belarusian taxi market, which use digital platform technologies, has led to a transformation in the market conditions. Not only the demand and supply for taxi services, barriers to entry into this market, the nature of competition have changed, but the labor market has also changed. Changes in the functioning of the taxi market led to the formation of contradictions, which the existing market regulation mechanism was not ready to resolve. Failures that cannot be eliminated through selfregulation of the market and require the development of other regulatory instruments have become obvious.

\section{PROBLEM STATEMENT}

The structure and architecture of the taxi market has changed significantly after the arrival of digital platforms in 
the Republic of Belarus. An analysis of the changes that have occurred allows one to identify common features with the nature of changes that have taken place in other national taxi markets, as well as some specific features characteristic of Belarus. The active penetration of transport network companies into the Belarusian taxi market occurred at the turn of 2015-2016. Uber entered the Belarusian market in November 2015, its main competitor in the post-Soviet space in this market segment, Yandex.Taxi, in November 2016.

The increase in the number of carriers and taxi cars, the number of passengers transported due to the entry of Uber into the taxi market, have been noted by many researchers (Gabel, 2016, Poó, Ledesma \& López, 2018, Beibei et al., 2018). This trend turned out to be typical for the Belarusian market as well. The number of entities operating taxis in the Republic of Belarus as of 01.01.2020 amounted to 7,441 and increased from the beginning of 2017 by $43.4 \%$. In the Republic of Belarus, in 2019, about 35 thousand passenger cars were involved in the implementation of irregular passenger transportation. This indicator for the period of 2017-2019 increased by about 30\%. The number of drivers working in this area can be estimated at about 44 thousand people, using all forms and conditions of employment. In the period of 2017-2019 in Belarus, the market share served by dispatched taxis has also grown (estimated at $80 \%$ ), which is largely due to the vigorous activity of aggregators and the advantages in service that they provide. In addition, transportation on the basis of a charter agreement and car rental with a crew have been developed (in the Republic of Belarus it is taken into account separately from transportation by taxi cars since 2019), which began to compete with traditional taxi transportation (reached $6 \%$ of the market).

The catalyst for growth was the introduction of digital platforms that allow ordering and paying for trips through a mobile application, which significantly increased the level of consumer comfort. On the one hand, sharing has led to a reduction in unit costs, on the other hand, it has made it possible to benefit from the implementation of economies of scale for ordinary users of applications, ensuring a reduction in transportation tariffs and increasing the possibilities and convenience of using taxi services. These consequences of digital platforms penetration into the Belarusian taxi market also correlate with global practice (Hall \& Krueger, 2018, Borowiak \& Ji, 2019, Garben, 2019). It should be noted that there is a positive cross-network effect typical for the functioning of multilateral digital platforms (Rochet \& Tirole, 2003) - an increase in the number of participants on one side of such platforms (customers) leads to an increase in the attractiveness of interaction for the other side of the platform (drivers), which also contributes to active growth market share of transport network companies (Cusumano, 2015).It should be noted that there have been significant changes in the labor market for taxi drivers, which are characteristic, in particular, for other national markets (Hall \& Krueger, 2018, Borowiak \& Ji, 2019, Berg \& Johnston, 2019).Not only the quantitative composition of taxi drivers is changing, the socio-demographic portrait of the driver is changing, their working conditions, the assessment of results and the degree of satisfaction are changing (Berger et al., 2019).

These changes cannot but affect the effectiveness of the implementation of existing regulatory instruments for this market (Dudley, Banister \& Schwanen, 2017, Darbera, 2017, Farren, Koopman \& Mitchell, 2016). At the same time, most of the requirements and regulations of the taxi market existing in the Republic of Belarus have changed only slightly compared to 2015 , when digital platforms were not presented in the Belarusian taxi market.

\section{RESEARCH QUESTIONS AND PURPOSE OF THE STUDY}

The hypothesis of this study is the assumption that the current procedure for regulating the Belarusian taxi market is not able to effectively resolve the contradictions objectively emerging in this market due to the penetration of digital platforms and technologies, which requires its significant modernization.

In this regard, the need arises:

- to identify specific features of the taxi market functioning in the Republic of Belarus;

- to identify objective contradictions in the market, the formation of which is due to the penetration of transport network companies into the Belarusian market, offering platform technologies and elements of the "sharing economy";

- to assess the ability of the current market regulation procedure to ensure the resolution of contradictions arising in the process of penetration of digital platforms;

- to determine contradictions that cannot be effectively eliminated using the market self-regulation mechanism or through the existing regulatory legal instruments of regulation by the state;

- to determine the main directions of regulation of the Belarusian taxi market.

\section{RESEARCH METHODS AND MATERIALS}

To solve the problem, the following were carried out:

- a systematic structured review of the literature in order to identify the features and adapt the mechanisms for regulating the taxi market to the conditions of digital platforms in individual countries;

- formation of a problem field for the implementation of current instruments for regulating the taxi market in the Republic of Belarus, taking into account the entry into it of the transport network companies Uber and Yandex.Taxi;

- research of the taxi market in the Republic of Belarus, its dynamics and structure;

- a survey of Belarusian taxi drivers;

- in-depth expert interviews.

A systematic structured literature review was carried out based on the analysis of the EBSCO and SPRINGER databases. The analysis of the taxi market was carried out according to the data of the National Statistical Committee and the materials of the Ministry of Taxes and Duties of the Republic of Belarus (WPC) for the period of 2017-2019. The research was supplemented by the results of a survey of drivers conducted by the industry laboratory of antimonopoly 
and price regulation, regulation in the sphere of trade of the Belarusian State Economic University in March-April 2020. 648 taxi drivers took part in the survey. 12 experts were interviewed.

\section{FINDINGS}

The study of the taxi market in the Republic of Belarus revealed the following development trends and specific features of its functioning.

The penetration of the Belarusian market by transport network companies contributed to a significant increase in market capacity, a change in its structure, as well as its fragmentation. If in 2017 a resident of Belarus covered an average of $19 \mathrm{~km}$ by taxi, then in 2019 this figure was 30.6 $\mathrm{km}$ per year. In 2017-2019 there was a significant increase in the passenger turnover of taxi cars (an increase of 60\%), the passenger turnover of taxis per capita increased by $61 \%$, and the highest growth rates are characteristic of the capital, Minsk (92\% in two years) and the capital region (an increase of $149 \%$ ). The pace of development of the taxi market in the capital and the metropolitan area is significantly ahead of other regions (the capital accounts for about half $(48.5 \%)$ of all passenger transportation by taxi cars and the share has increased by almost 20 percentage points over the past two years. Despite this, in all regions there is an increase in the number of cars carrying out irregular urban passenger traffic, per 1000 people. The highest rates of change were also observed in Minsk (6.5 cars per 1000 people), for comparison, according to the Analytical Center for the Government of the Russian Federation, the same indicator in Moscow, the capital of Russia, and the agglomeration in the first half of 2019 was 6.0.

The national market is characterized by a high level of competition. At the same time, the number of taxi carriers is steadily increasing — for the period of $2017-2019$ by $43.4 \%$, including only in 2019 - by $29 \%$. The increase in the number of carriers and the expansion of options for the provision of related services was largely a consequence of the reduction in barriers to market entry. Reducing barriers to entry into the taxi market as a result of the emergence of digital platforms has been noted as a general trend by a number of researchers (Gabel, 2016, Hall \& Krueger, 2018, Borowiak \& Ji, 2019, Spicer, Eidelman \& Zwick, 2019). On the other hand, in November 2017, the licensing of this type of activity that had been in force earlier was actually canceled in the Republic of Belarus. The need to obtain a license complicated the procedure for starting to operate in the taxi market and required additional initial costs, in particular, the necessity to pay the state fee for issuing a license. This is especially relevant, given that the legislation of the Republic of Belarus does not impose specific requirements on the subject composition of carriers of passengers by road (the share of individual entrepreneurs in the total number of participants in the Belarusian taxi market is $87.8 \%$, the share of organizations is $12.2 \%$ ). According to the survey, the average cost of a trip made through a digital platform was $51 \%$ lower, while the average length of a trip booked through the platforms was only $12 \%$ lower. Thus, the fare per $\mathrm{km}$ for trips ordered using digital technologies was $44 \%$ lower. Obviously, such a difference in tariffs is due not only to cost savings due to the manifestation of economies of scale, but to a greater extent to a decrease in the cost of car maintenance, security, incl. insurance, as well as in the average earnings of drivers.

The employment market and the forms of labor organization have undergone significant changes. According to the results of a survey conducted by the industry laboratory of antimonopoly and price regulation, regulation in the sphere of trade of the Belarusian State Economic University in March-April 2020, employment in this area is the only source of income for $58 \%$ of drivers. At the same time, there are differences in the shares of such drivers among those who work with digital platforms (for $55.2 \%$ this is the only income, for $11.7 \%$ - the main one, for $32.9 \%$ - extra earnings), and those who do not use the services of aggregators taxi (for $63.8 \%$ this is the only income, for $8.7 \%$ - the main one, for $27.5 \%$ - extra earnings). It should be noted that a feature of the Belarusian market is, in general, a high proportion of drivers, for whom this is the only source of income. In comparison, a 2015 U.S. study (Hall \& Krueger, 2018) found that 52\% of Uber partner drivers worked full-time at another job, and only $33 \%$ of partner drivers did not have another job.Such differences may be due to a significant difference in the minimum length of the working day required to obtain the minimum acceptable level of wages.For example, more than $65 \%$ of the surveyed drivers using digital platforms in Belarus noted that the average working day exceeds 9 hours.

While maintaining a high relationship between the amount of income remaining at the disposal of drivers and the number of orders executed per day, there was a decrease in income per 1 trip with an increase in the number of orders, which indicates both a greater share of short trips and a lower profitability of one trip made using digital platforms. Thus, while recognizing the increased flexibility in work and in the choice of working hours when working with digital platforms, it should be noted that the low level of income of drivers in the Republic of Belarus forces them to increase their working hours, which negates the benefits of working with Uber. In this regard, it is advisable to assess the proportion of those who are going to change their field of activity in the near future. The share of such drivers for the group of drivers who do not use the services of aggregators was $43.5 \%$ versus $59.7 \%$ among those who use their services. Thus, a specific feature of the Belarusian taxi market at present is the lower value of such a factor as the flexibility of the driver in choosing a taxi aggregator.

Also, a feature of the Belarusian taxi market, according to the survey, is that the majority $(62 \%)$ of vehicle drivers are the owners of the vehicles they use for transportation. At the same time, the share of such drivers among partners of Uber and Yandex.Taxi is over $65 \%$.

There are significant differences in the socio-economic profile of taxi drivers. Thus, in Belarus, the share of women in the total number of taxi drivers was less than $4 \%$ according to the survey. For example, in the United States, the proportion of women among taxi drivers is about $8 \%$ (Hall \& Krueger, 2018). 63\% of the respondents in Belarus turned out to be under 39 years old, the share of elderly drivers (age 65+) was less than $4 \%$ of the respondents. The average earnings remaining at the disposal of the driver was unevenly distributed, however, less than a third of drivers receive earnings comparable to or higher than the average wage in 
the country, respectively, more than $67 \%$ of the respondents indicated the amount of earnings below or significantly below the national average. Among those who use the services of digital platforms, the share of such drivers was even higher $(75.7 \%)$.

The Belarusian taxi market is characterized by a high share of the shadow sector. Thus, the weighted average expert assessment of the share of the illegal (shadow) market in the total volume of the irregular road passenger transport market in 2019 was about $30 \%$, and the growth rate of the illegal market segment, according to the agreed opinion of experts, exceeds the growth rate of its legal part;

The effectiveness of the applied market regulation instruments has decreased:

- the implementation of transportation using digital platforms did not actually fall under the regulation established for transportation by taxi cars, because initially such transportation was considered as freight from the point of view of Belarusian legislation;

- only about $40 \%$ of the cars being used are equipped with a taximeter, while the average distance of drivers' trips with a taximeter installed on a car is $10 \%$ higher than on a car without a taximeter $(7.5 \mathrm{~m}$ versus 6.8 $\mathrm{km})$;

- only a third of taxi drivers always issue a check, one quarter do not offer the check themselves, but give it out at the request of the passenger, however, almost a quarter of taxi cars are not equipped with a cash register at all, which, accordingly, implies the impossibility of issuing a check;

- organizations have an overwhelming share (98\%) of budget revenues; at the end of 2019, the average individual entrepreneur employed in this area provided payments to the budget in the amount of 1.71 thousand rubles per year, whereas organizations 204.1 thousand rubles (gap more than 119 times).

The study made it possible to identify certain problems that exist in the taxi market in the field of adapting the current regulatory standards to digitalization processes:

- the abolition of licensing in the field of taxi transportation significantly affected the mechanisms of tax accounting, the number, composition and structure of entities involved in the transportation of passengers using taxi cars, as well as the amounts of payments transferred to the budget for this type of activity;

- there is no complexity, consistency and a unified methodology of the information collected between various departments involved in the regulation of this field of activity;

- a decrease in the level of safety and discipline of compliance with the requirements of the Road Traffic Regulations, including by taxi drivers, which was noted by the Transport Inspectorate, namely, in the field of irregular transportation of passengers (taxis) in 2019, in comparison with 2017, 7.4 times more violations were revealed, including: failure by the driver to undergo a pre-trip medical examination, violation by the driver of the work and rest regime, use of cars without permission to participate in road traffic, transportation of passengers with malfunctions in the presence of which participation in road traffic is prohibited;

- the adoption of the changes influenced the state of the market and amendments to the Rules for the carriage of passengers by road, according to which taxi dispatchers or car carriers who independently receive and transmit orders for taxi transportations using the Internet, the owners of electronic information systems are obliged to provide information on the completed road carriage of passengers in the form an electronic document to the relevant inspectorates of the Ministry of Taxes and Tax Collection, which led to the formation of a data bank on the performed road transportations by taxi cars in general, as well as performed transportations ordered using digital platforms in particular.

The results of the study allow one to conclude that there are peculiarities in the transformation of the taxi market due to the entry into the market of digital platforms and the low efficiency of the mechanism used to regulate the taxi market in the Republic of Belarus. Various ministries and departments have used, with varying degrees of effectiveness, individual levers and regulatory instruments that do not have signs of consistency, complexity and focus on the long term.

For the Republic of Belarus it is also relevant:

- state regulation of the taxi market as one of the goals involves the solution of social issues and the achievement of public interests;

- unresolved conflict of interests of the taxi market entities leads to creation of discriminatory conditions in relation to individual market participants;

- multidirectionality and inconsistency of instruments used by various departments to regulate the taxi market;

- the orientation of procedures and levers for a shortterm period of impact, which aggravates the situation of uncertainty in the market, generates additional risks and does not allow subjects to develop a long-term strategy of behavior.

In international practice, two models of taxi market regulation are most often used: conservative and progressive. However, none of the models so far systematically considers the impact of new technologies and digital systems, evaluates shared relationships, and evaluates network and crossplatform effects. This implies the need to develop its own mechanism, taking into account the emerging trends and the positive experience of other countries.

\section{CONCLUSION}

In the Republic of Belarus, there are significant structural shifts and changes in the taxi market, largely due to the emergence of the transport network companies Uber and Yandex.Taxi. These transformations led to a crisis in traditional forms of business organization and market 
regulation mechanism. The use of international experience does not allow for direct copying of the used regulation models, since the state of the national taxi market has significant differences from the markets of other countries; the epistemology, capacity and scale, as well as the tasks to be solved, are different. At the same time, the use of effective tools that have proven themselves in practice, and their inclusion in an integral system aimed at solving specific goals, is quite expedient.

The arrival of aggregators on the market of irregular road passenger transportation in the Republic of Belarus led to the growth and rapid development of the market and had both positive and negative aspects for the area under consideration, which, in general, is in line with global practice (for example, Zwick \& Spicer, 2018, Gyodi, 2017). The positive aspects are: reduction in the cost of services provided; convenience, attractiveness for both passengers and drivers; an increase in the number of cars and drivers involved in the work; increase in tax payments to the budgets of the corresponding levels; renewal of the car park; activation of the development of information technologies, non-cash payments; reduction of idle mileage of cars. The negative aspects were associated with: limiting leverage in the field of passenger taxi transportation; the loss of full control by government bodies over activities in the field of passenger transportation by taxi cars; a large number of illegal immigrants were involved in the transportation process, the number of unregistered carriers increased, the number of carriers that did not meet the requirements for taxi cars increased; the market for established car taxi fleets collapsed, the work of a classic taxi has ceased to be profitable, the "life" of classic taxi drivers has become more complicated; the safety of transportation and the degree of compliance with the Rules for the carriage of passengers decreased.

The study allows one to characterize the average portrait of a Belarusian taxi driver as follows: a man of 26-45 years old, works alone in his car almost daily for more than 9 hours, performs 10-20 orders per day, which, on average, takes about half an hour, in a car, most likely, there is no taximeter, but there is a possibility of issuing a check, when the client asks for it himself, travels short distances (up to $10 \mathrm{~km}$ ) in his city and its surroundings, the average cost of one order is 4-8 rubles, carries 1- 2 people per trip, receives revenue of 75-85 rubles per day, works through an aggregator, passenger transportation is the main source of income with a net income per month from 600 to $900 \mathrm{BYN}$, which is lower than the national average, and therefore he is thinking about change of occupation.

Taking into account the formed problem field and the results of the taxi market research, the developed regulatory mechanism may include the following tools, levers and incentives:

- creation of a unified methodology for accounting and collection of information, a unified information platform for accounting and quality control and safety of passenger transportation;

- assessment of the feasibility of reintroducing the licensing of non-scheduled passenger traffic in order to strengthen market supply regulation and control, including over the safety of transportation;
- introduction of a local tax on every taxi ride, while developing a system of incentives for aggregators to register for .by and .bel domain names, including by exemption from local tax payments;

- development of a domestic application using digital technologies for national dispatch taxis in order to increase their ability to compete with transport network companies;

- development of amendments to regulations with the aim of introducing the status of "self-employed" (taking into account the experience of the Russian Federation) and obtaining a permit to work as a taxi for your personal car, which will reduce the share of the shadow market and the level of unemployment;

- use of telematics as a system for remote control over the state of the car, which will allow more accurate control of the operation of the vehicle fleet and the work of drivers, reducing costs and optimizing processes within the business;

- creating conditions for the development and testing of unmanned vehicles on the national market, providing for their operation initially only in taxi services, and not for personal use, which will help increase travel safety, the possibility of greater control, and reduce the cost of travel;

- widespread use of information technologies to tighten control over the safety of transportation: the use of a satellite GPS monitoring system, devices for monitoring attention and fatigue; remote monitoring of speed and driving style; control of time spent on the line;

- improvement of the insurance system, taking into account the peculiarities of the functioning of transport network companies.

\section{References}

[1] H. Beibei, Ya. Kong, M. Sun, X. Dong and G. Zong, "Understanding The Unbalance Of Interest In Taxi Market Based On Drivers' Service Profit Margins", PLoS ONE. 6/18/2018, vol. 13(6), pp. 1-18. DOI: 10.1371/journal.pone.0198491

[2] J. Berg and H. Johnston, "Too Good to Be True? A Comment on Hall and Krueger's Analysis of the Labor Market for Uber's DriverPartners", ILR Review, Jan2019, vol. 72(1), pp. 39-68. DOI: 10.1177/0019793918798593

[3] T. Berger, C. Frey, L. Benedikt, D. Guy and S.R. Danda, "Uber happy? Work and well-being in the "Gig Economy"”, Economic Policy, 2019, vol. 34(99), pp. 429-477. DOI:10.1093/epolic/eiz007

[4] C. Borowiak and M. Ji, "Taxi Co-Ops Versus Uber: Struggles For Workplace Democracy In The Sharing Economy", Journal of Labor \& Society, 2019, vol. 22(1), pp. 165-185. DOI: 10.1111/wusa.12388

[5] M.A. Cusumano, "How Traditional Firms MustCompete in the Sharing Economy Communications of the ACM”, 2015, vol. 58(1), pp.32-34. DOI: $10.1145 / 2688487$

[6] R. Darbera, "What regulation for the taxi of the future?", International Road Union (IRU), 2017. Retrieved from: https://hal.archivesouvertes.fr/hal-01631667

[7] G. Dudley, D. Banister and T. Schwanen, "The Rise of Uber and Regulating the Disruptive Innovator", Political Quarterly, 2017, vol. 88(3), pp. 492-499. DOI: 10.1111/1467-923X.12373 
[8] M. Farren, Ch. Koopman and M. Mitchell, "Rethinking Taxi Regulations: The Case for Fundamental Reform", Research Papers, Mercatus Center at George Mason University, Washington July 19, $2016 . \quad$ Retrieved from: https://www.mercatus.org/publications/corporate-welfare/rethinkingtaxi-regulations-case-fundamental-reform

[9] D. Gabel, "Uber and the Persistence of Market Power", Journal of Economic Issues, 2016, vol. 50(2), pp. 527-534. DOI: 10.1080/00213624.2016.1179060

[10] S. Garben, "The regulatory challenge ofoccupational safety and healthin the online platform economy", International Social Security Review, 2019, vol. 72, p.95-112.

[11] K. Gyodi, "Uber vs Licensed Taxi Drivers: A War Between Technological Standards", Working Paper DELab UW, 2017, vol. 2(2017).
[12] J.V. Hall and A.B. Krueger, "An Analysis of the Labor Market for Uber's Driver-Partners in the United States”, ILR Review. 2018, vol. 71(3), pp. 705-732. DOI: 10.1177/0019793917717222

[13] F.M. Poó, R.D. Ledesma and S.S. López, "The Taxi Industry: Working Conditions And Health Of Drivers, A Literature Review", Transport Reviews, 2018, vol. 38(3), pp. 394-411. DOI: https://doi.org/10.1080/01441647.2017.1370035

[14] J.C. Rochet and J. Tirole, "Platform Competition In Two-Sided Markets", Journal of the European Economic Association, 2003, pp. 990-1029.

[15] Z. Spicer, G. Eidelman and A. Zwick, "Patterns of Local Policy Disruption: Regulatory Responses to Uber in Ten North American Cities", Review of Policy Research, 2019, vol. 36(2), pp. 146-167. DOI: $10.1111 /$ ropr.12325

[16] A. Zwick and Z. Spicer, "Good or bad? Ridesharing's impact on Canadian cities”, CanadianGeographer, 2018, vol. 62(4), pp. 430-436. DOI: $10.1111 / \mathrm{cag} .12481$ 